\title{
Delayed Facial Palsy after Head Injury - A Prospective Study Conducted at a Tertiary Care Centre
}

\author{
Lt. Col. Ravindra Dubey ${ }^{1}$, Sunil Panchal2 ${ }^{2}$ Junaid Ahmed ${ }^{3}$, Manoj Agarwala ${ }^{4}$ \\ ${ }^{1}$ Department of ENT, Military Hospital, Jaipur, Rajasthan, India. ${ }^{2}$ Department of Neurosurgery, GNRC Institute of \\ Medical Sciences, GNRC North Guwahati, Assam, India. ${ }^{3}$ Department of Neurosurgery, GNRC Institute of Medical \\ Sciences, GNRC North Guwahati, Assam, India. ${ }^{4}$ Department of ENT, GNRC Institute of Medical Sciences, GNRC North \\ Guwahati, Assam, India.
}

\section{ABSTRACT}

\section{BACKGROUND}

Facial nerve injury after head injury is not very uncommon, but delayed facial palsy (DFP) which occurs after many days of head injury, is a rare phenomenon. The mechanism is not clear, and there has been no detailed study on this condition. We conducted this study, with an aim to estimate this complication of head injury, and to study its pathogenesis, natural history, prognosis, and sequelae which differ markedly from Bell's palsy.

\section{METHODS}

This prospective study, included 70 patients, admitted to the Department of Neurosurgery GNRC Institute of Medical Science, North Guwahati, from October 2018 to July 2019. Parameters noted were, age, sex, mode of injury and part of temporal bone fractured. Patients were observed for CSF otorrhoea, features of facial palsy, acute/delayed complete/incomplete recovery/ no recovery. End point is complete recovery or 3 months

\section{RESULTS}

Delayed facial palsy was seen in 3 out of 70 patients, (4.28\%) patients, having fracture petrous bone, (longitudinal and mixed). Age, sex, mode of injury did not have any influence on occurrence of DFP.

\section{CONCLUSIONS}

Close monitoring, and early realization of the cranial nerves related deficit such as facial palsy, acute or delayed, is the key for better management, documentation, counseling and medico legal aspects.

\section{KEY WORDS}

Head Injury, Delayed, Facial Palsy
Corresponding Author:

Dr. Sunil Panchal,

Consultant,

Department of Neurosurgery,

GNRC Institute of Medial Sciences,

North Guwahati, Assam, India.

E-mail: psunil437@gmail.com

DOI: $10.14260 / \mathrm{jemds} / 2019 / 820$

Financial or Other Competing Interests: None.

How to Cite This Article:

Dubey R, Panchal S, Ahmed J, et al. Delayed facial palsy after head injury- a prospective study conducted at a tertiary care centre. J. Evolution Med. Dent. Sci. 2019;8(50): 3785-3789, DOI: $10.14260 /$ jemds $/ 2019 / 820$

Submission 10-06-2019, Peer Review 16-11-2019,

Acceptance 05-12-2019,

Published 16-12-2019. 


\section{BACKGROUND}

Idiopathic facial palsy, which is also known as Bell's palsy is the most common cause of facial nerve palsy.[1] Bell's palsy presents as an acute unilateral paresis or paralysis of the face in a pattern consistent with dysfunction of peripheral nerve without evident causes.[2] About 5 per cent of all cases of facial paralysis results from head injuries.[3] Facial palsy after head injury can be acute or delayed. Delayed facial palsy after head injury, facial palsy which is not noticed immediately but seen after some time. A known entity not so commonly seen, the mechanism is not clear, and there has been no detailed study on this condition. It is common due to fracture of the temporal bone with transaction or compression of the facial nerve. It is typically unilateral or can be complete or partial. In cases where the nerve injury is incomplete or delayed, prognosis is excellent. The most common cause of unilateral facial paralysis after the trauma is fracture of the temporal bone with either compression place on the facial nerve by displacement of the bony fragments, soft tissue oedema, localized hematoma, or traumatic disruption of the nerve. May be delayed arterial spasm, thrombosis or external compression from bony fragment or soft tissue oedema. ${ }^{[4]}$

In the facial canal, the area occupied by the facial nerve is only $30-50 \%$ of the cross-sectional area of the canal. The remainder of the facial canal is occupied by blood vessels with connective tissue loosely arranged around the nerve. Delayed facial palsy is possibly the result of bleeding into the facial canal. An increasing size of a hematoma in the limited non-expanding bony tube could press on the facial nerve. If the pressure were of a mild degree, there would only be a neuropraxia, or conductive block due to segmental demyelination. If the damage were more severe, there could be axonal damage with denervation. If facial palsy develops immediately after the trauma it indicate that either nerve is completely lacerated or contused but delayed onset indicates other causes as mentioned above. Vascular disturbances consequent upon oedema is the probable cause of delayed onset of palsy in this case as supported by Brusati \& Paini. Sometimes appears within one week and sometimes within two to three weeks. Facial palsy whether acute in onset (seen with onset of trauma or delayed), may be complete of incomplete, if it is having only subtle signs can only be picked up after meticulous examination. Thus, meticulous and regular examinations are the key to pick up and differentiate acute onset and DFP. This is useful in documentation and needful approach towards treatment.

Temporal bone fractures are classified either according to their orientation (transverse versus longitudinal) relative to the long axis of the petrous bone or based on their involvement of the otic capsule (otic capsule sparing versus otic capsule violating). Incidence wise Longitudinal and transverse fracture differs significantly $(70 \%$ and 30\%) respectively. CSF leak or Otorrhoea is more common in longitudinal as compared to transverse fracture. Facial nerve injury is less common and is mostly less severe or delayed as compared $t$ transverse where it is generally acute in onset and more severe. Turner (1944) studied a selected group of war-time head injuries from a military hospital for head injuries, and found an incidence of $2.2 \%$ developing a delayed facial palsy.[5] Potter (1964), in his study, found the incidence of this complication of head injury as about
$0.6 \%{ }^{[6]}$ Both authors have cautioned about the difficulty in detecting an immediate facial palsy and which may result in wrong classification as delayed facial palsy.

\section{METHODS}

This study was conducted at the GNRC Medical, North Guwahati and Department of Neurosurgery. This is a tertiary care hospital and caters for the patient reporting for treatment from Guwahati, neighboring districts and states for treatment.

\section{Inclusion Criteria}

1. All patients of head injury with CSF Otorrhoea or ear bleeding.

2. Head injury with temporal bone fracture.

3. Age $15-60$ years.

\section{Exclusion Criteria}

1. Head Injury with GCS below 8 .

2. Patients having multiple facial injuries.

This prospective cohort study, included 70 patients, admitted to the Department of Neurosurgery GNRC institute of Medical science North Guwahati, from October 2018 to July 2019. All cases selected for study were studied from the day of reporting to the hospital to the evolution of the delayed facial palsy. All those patients who developed facial palsy were subjected to HRCT Temporal bone. Cochlear, vestibular, and middle-ear functions are also studied in these cases in detail because of their close anatomical relation to the 7 th nerve. Detailed neurological examination of other cranial nerves was also done. We followed our patients on weekly basis. End point is complete recovery or 3 months.

\section{RESULTS}

Study started in October 2018 and completed in July 2019, we included 70 cases of head injury with temporal bone fracture as per our inclusion criteria. Mean age of patients in our study was 39.4 \pm 11.41 years (range, 20-60 years). We have divided our patients in four groups as per their age, maximum number of patients were from $30-40$ years (22) Figure 1 . Out of total 70 patients 66 were male and 4 were female patients Figure 2. We have noticed delayed facial palsy (DFP) in 3 patients, out of the 70 patients studied only 20 patients had petrous bone fracture and 50 patients had fracture of squamous part of temporal bone. Out of the 20 patients, 7 patients had longitudinal fracture and 2 had transverse fracture and 11 had mixed/oblique, out of the 7 patients who had longitudinal fracture 4 had transient CSF Otorrhoea, one developed meningitis and one had DFP incomplete Figure 3.

Road traffic accident was the most common mode of injury 60, followed by fall and assault Figure 4 . Out of the 2 patients who had transverse fracture 1 patient had acute onset of facial palsy complete and no delayed facial palsy. Out of the 11 patients who had mixed/oblique fracture 5 had CSF 
Otorrhoea and 2 had features of meningitis and 2 had delayed onset facial palsy Table 1 . Onset of delayed facial palsy was noted less than one week in one patient and second week in two patients Table 2 .

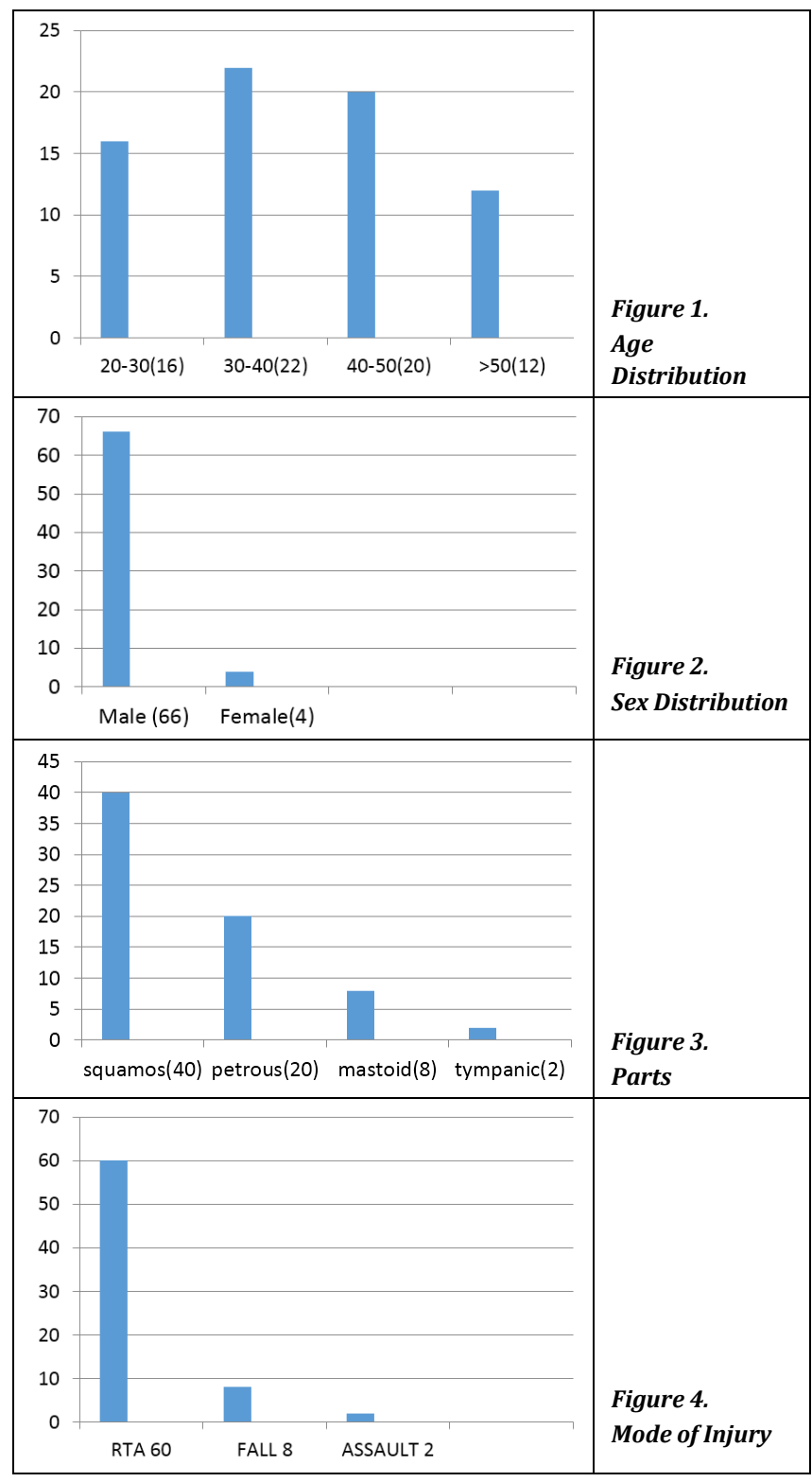

\begin{tabular}{|c|c|c|c|c|}
\hline \multirow{2}{*}{$\begin{array}{c}\text { Part of Temporal } \\
\text { Bone Involved }\end{array}$} & \multirow{2}{*}{$\begin{array}{c}\text { Squamous } \\
\mathbf{5 0}\end{array}$} & $\begin{array}{c}|c| \\
\text { Pongitudinal }\end{array}$ & $\begin{array}{c}\text { Transverse } \\
\mathbf{7}\end{array}$ & $\begin{array}{c}\text { Mixed } \\
\mathbf{1 1}\end{array}$ \\
\hline Facial palsy acute & 0 & 0 & 1 & \\
\hline DFP & 0 & 1 & 0 & 2 \\
\hline Table 1. All Three Patients of Delayed Facial Palsy had \\
Fracture of Petrous Bone \\
\hline
\end{tabular}

\begin{tabular}{|c|c|c|}
\hline Onset & < D Days & 7-14 Days \\
\hline Number & 01 & 02 \\
\hline \multicolumn{2}{|c|}{ Table 2. Onset of Delayed Facial Palsy } \\
\hline \multicolumn{2}{|c|}{}
\end{tabular}

\section{DISCUSSION}

Cranial nerve VII (the facial nerve) is a mixed nerve with both motor and sensory components. Fibers from the motor division supply the facial mimetic musculature, the stapedius, the stylohyoid, and the posterior belly of the digastric.[7,8]
Fibers of the motor division arise from the motor facial nucleus, which lies in the reticular formation of the caudal pontine tegmentum, dorsal to the superior olive, medial to the nucleus of the spinal tract of cranial nerve $V$ (Trigeminal nerve), and anterolateral to the nucleus of cranial nerve $\mathrm{VI}$ (Abducens nerve).The facial nucleus is made up of four separate longitudinally oriented cell groups (sub-nuclei) that supply specific muscle groups.[9] After emerging from the ventrolateral pons, the motor division and the nervus intermedius proceed laterally in the cerebellopontine angle along with cranial nerve VIII. This nerve then enters the internal auditory meatus of the temporal bone together with the auditory nerve and the internal auditory artery and vein. Four portions of the facial nerve can be distinguished within the temporal bone.

The meatal (canal) segment, the labyrinthine segment, the horizontal (tympanic) segment, the mastoid (vertical) segment. Facial paralysis can be partial or complete. Diagnosis requires identification of the involved side, underlying aetiology, and clinical grading. Many systems for reporting grading of facial function have been proposed. The American Academy of Otolaryngology-Head and Neck Surgery adopted the House-Brackmann six-point subjective grading system as its standard.[10,11,12] Road traffic accidents accounts for most common cause of traumatic temporal bone fractures. In facial palsy after closed head injury, a fracture of the base of the skull is usually assumed to be present.[13] The temporal bone is affected in more than one third of basilar fractures.[14] Temporal bone fracture and associated facial nerve injury is a known entity, sometimes there can be bilateral temporal bone fracture which are unusual. [15] Temporal bone fracture is a well-known cause of facial paralysis, and is responsible for approximately 3 per cent of bilateral facial paralysis. $[16,17,18,19]$

In our cases, all those who had a facial palsy had fracture of the petrous bone and bleeding ear or CSF Leak. Fractures of the temporal bone are classified in longitudinal or transverse in dependence of preservation or destruction of the inner ear. Petrous bone fractures that cause facial paralysis are either transverse or longitudinal or oblique/mixed. Transverse fractures are uncommon and account for only $20-30 \%$ of temporal bone fracture.[20] Transverse fracture rarely causes bleeding from the ear or fractures of external auditory canal. Facial nerve palsy occurs in $30-50 \%$ of transverse fractures, and the paralysis is likely to be immediate in onset and complete because of nerve disruption. ${ }^{[21,22,23]}$

The onset of facial palsy may be immediate or delayed. Immediate facial palsy occurs due to stretching/ compression/crushing/division of the nerve. Up to $70-80 \%$ of all petrous fractures are longitudinal. Unlike the former type, longitudinal fracture very often passes through the external auditory canal, and usually tears the tympanic membrane producing bleeding from the external auditory canal. Facial paralysis occurs in 10-25\% of these cases. The onset of paralysis is usually delayed. In our study longitudinal fracture is more common than transverse and leak is more seen in longitudinal and DFP is seen more common in longitudinal than transverse.

In the facial canal, the area occupied by the facial nerve is only $30-50 \%$ (at its greatest width) of the cross-sectional area of the canal. The remainder of the facial canal is 
occupied by blood vessels with connective tissue loosely arranged around it.[24] In immediate facial palsy it is easily assumed that the fracture damages or causes severance of the facial nerve. Delayed facial palsy is possibly the result of bleeding into the facial canal. Increasing size of a hematoma in the limited non-expanding bony tube could press on the facial nerve ultimately cut off its blood supply, causing ischemic damage to the nerve. If the pressure were mild, there would be only a neuropraxia or conduction block due to segmental demyelination. If the damage were more severe, there could be axonal damage with denervation. The rapid progression of a delayed palsy to a complete paralysis is usually due to formation of an intraneural hematoma at the area of geniculum. If the hematoma is not rapidly eliminated, fibrosis and even ossifications will make recovery of function impossible. In longitudinal fractures the typical lesion site is around the geniculate ganglion. Similar mechanism is seen in bell's palsy, inflammatory reaction in and around the nerve, or a swelling of the nerve in the canal which could lead to ischemia.

Picking up of cranial nerve deficit in head injury patients is not an easy task, due to the severe nature of the injury, associated cognitive and affective deficits and other secondary complications. Investigations such as highresolution CT, contrast enhanced MR imaging, provides significant help in such cases.[25,26,27] Thus we recommend all cases of temporal bone fractures should be carefully observed for the development of facial palsy. This can be acute or delayed. And help appropriate investigations should be taken.

\section{Limitations}

Our study is based on the data collected from single centre. Our center being a tertiary care referral hospital having significant number of patients getting referred from peripheral hospital and these patients are generally in poor conditions and can affect the incidence of outcome also. In spite of being a higher hospital, it lacks world class facilities of care which can definitely affect the outcome of patients. A larger sample size and multiple institution data may give the better idea about prevalence natural history and establishment of guidelines for cases of delayed facial palsy.

\section{CONCLUSIONS}

Traumatic brain injury is an epidemic and is invariably associated with a number of complications. Delayed facial palsy following traumatic brain injury is not a common finding with very low incidence, with high chances of missing the diagnosis. Early diagnosis of facial paralysis in traumatic brain injury can be particularly challenging due to the severe nature of the injury, associated cognitive and affective deficits and other secondary complications. Since fracture of temporal bone is commonly seen with base of skull fracture, some of them may develop acute or delayed facial palsy. Such patients require close monitoring, early realization of the cranial nerves related deficit helps in better management and documentation which is helpful in medico legal aspects.

\section{REFERENCES}

[1] Danielides V, Patrikskos G, Christina-Sophia N, et al. Weather conditions and Bell's palsy: five year study and review of the literature. BMC Neurology 2001;1:7.

[2] Bell C. On the nerves: giving an account of some experiment on their structure and functions which lead to a new arrangement of the system. Phil Trans of the Royal Soc of Lond 1821;111:398-428.

[3] Steenerson RL. Bilateral facial paralysis. Am J Otolaryngology 1986;7(2):99-103.

[4] Hwang JY, Jwa CS, Kim KH, et al. Post-traumatic bilateral facial paralysis. A case report. J Kor Neurotraumatol Soc 2006;2(2):136-9.

[5] Turner JWA. Facial palsy in closed head injuries. Lancet 1944;246:756-7.

[6] Briggs M, Potter JM. Prevention of delayed traumatic facial palsy. British Medical Journal 1967;4(5577):464-5.

[7] Afifi AK, Bergman RA. Functional neuroanatomy. Text and atlas pons. New York: McGraw-Hill Publications 1998: p. 147-78.

[8] Brodal A. Neurological anatomy in relation to clinical medicine. $3^{\text {rd }}$ edn. New York: Oxford University Press 1981: p. 495-508.

[9] Carpenter M. Core text of neuroanatomy. Baltimore, MD: Williams \& Wilkins 1985: p. 151.

[10] Croxson G, May M, Mester SJ. Grading facial nerve function: House-Brackmann versus Burres-Fish methods. AM J Otol 1990;11(4):240-6.

[11] House JW, Brackmann DE. Facial nerve grading system. Otolaryngol Head Neck Surg 1985;93(2):146-7.

[12] Yen TL, Driscoll CL, Lalwani AK. Significance of HouseBrackmann facial nerve grading global score in the setting of differential facial nerve function. Otol Neurotol 2003;24(1):118-22.

[13] Puvanendran K, Vitharana M, Wong PK. Delayed facial palsy after head injury. Journal of Neurology, Neurosurgery and Psychiatry 1977;40(4):342-50.

[14] Lee GY, Halcrow S. Petrous to petrous fracture associated with bilateral abducens and facial nerve palsies: a case report. J Trauma 2002;53(3):583-5.

[15] Sherwen PJ, Thong NC. Bilateral facial nerve palsy: a case study and literature review. J Otolaryngol 1987;16(1):28-33.

[16] Glasscock ME 3rd, Wiet RJ, Jackson CG, et al. Rehabilitation of the face following traumatic injury to the facial nerve. Laryngoscope 1979;89(9 Pt 1):1389404.

[17] Hartley C, Mendelow AD. Post-traumatic bilateral facial palsy. J Laryngol Otol 1993;107(8):730-1.

[18] Li J, Goldberg G, Munin MC, et al. Posttraumatic bilateral facial palsy: a case report and literature review. Brain Injury 2004;18(3):315-20.

[19] Teller DC, Murphy TP. Bilateral facial paralysis: A case presentation and literature review. J Otolaryngol 1992;21(1):44-7.

[20] Tos M. Fractura ossis temporalis. Forlobet og folger of 248 petrosafrakturer. Ugesker Laeger 1971;13(1):114956. 
[21] McHugh HE. Surgical treatment of facial paralysis and traumatic conductive deafness in fractures of temporal bone. Annals of Otology, Rhinology and Laryngology 1959;68:855-89.

[22] Harker LA, McCabe BF. Temporal bone fractures and facial nerve injury. Otolaryngologic Clinics of North America 1974;7(2)425-31.

[23] Miehlke A. Recognition and management of facial nerve palsies of operative and traumatic origin. Proceedings of the Royal Society of Medicine 1973b;66(6):549-54.

[24] Sunderland S, Cossar DF. The structure of the facial nerve. Anatomical Record 1953;116(2):147-65.
[25] Darrouzet V, Duclos JY, Liguoro D, et al. Management of facial paralysis resulting from temporal bone fractures: our experience in 115 cases. Otolaryngol Head Neck Surg 2001;125(1):77-84.

[26] Cannon CR, Jahrsdoerfer RA. Temporal bone fractures. Review of 90 cases. Arch Otolaryngol 1983;109(5):2858.

[27] Kinoshita T, Ishii K, Okitsu T, et al. Facial nerve palsy: evaluation by contrast-enhanced MR imaging. Clinical Radiology 2001;56(11):926-32. 